\title{
An Exploratory Study of Diversity Statements in Canadian Academic Librarian Job Advertisements
}

\author{
Norda Bell, York University Libraries, Canada
}

\begin{abstract}
Diversity statements signal an organization's culture, values, and commitment to diversity and inclusion. Yet, diversity statements are often perceived as somewhat superficial "boilerplate" or basic statements created to comply with employment equity requirements, especially in job advertisements. With the objectives of understanding the presence of diversity statements in job advertisements, differences between types of libraries, and the types of diversity statements and messages contained in these statements, this study analyzed the diversity statements of 50 online job advertisements for Canadian academic librarian and archivist positions. Four types of diversity statements were identified from this study: Type 1) boilerplate; Type 2) employment equity; Type 3) diversity; and Type 4) expanded diversity management. Findings suggest most Association of Research Libraries (ARL) member institutions in Canada have expanded diversity management statements. Other findings around land acknowledgements, gender identity, and sexual orientation and others are discussed. Recommendations for further studies are included.
\end{abstract}

Keywords: academic libraries; Canada; diversity statements; employment equity; inclusion; job advertisements; qualitative content analysis

Publication Type: research article

\section{Introduction}

D iversity, equity, and inclusion (DEI) are generally regarded as accepted core professional values in librarianship with leading library associations indicating their commitment to DEI in their mission statements and strategic priorities, including the American Library Association (ALA) and its affiliates (American Library Association, 2020). The Association of Research Libraries (ARL), another important library and information science (LIS) organization in North America, endeavors to "create diverse, equitable, inclusive, and accessible work environments, services, and collections" (2020, para. 4) as part of their strategic priorities.

When discussing DEl topics, it is important to start with an understanding of the three concepts, as definitions of these concepts are often absent from the literature. The ALA (2017) defines and distinguishes the concepts of equity, diversity, and inclusion:

"Equity" takes difference into account to ensure a fair process and, ultimately, a fair outcome. Equity recognizes that some groups were (and are) disadvantaged in accessing educational and employment opportunities and are, therefore, underrepresented or marginalized in many organizations and institutions. Equity, therefore, means increasing diversity by ameliorating conditions of disadvantaged groups.

The International Journal of Information, Diversity, \& Inclusion, 5(3), 2021

ISSN 2574-3430, https://jps.library.utoronto.ca/index.php/ijidi

DOI: $10.33137 /$ ijidi.v5i3.36202 
"Diversity" can be defined as the sum of the ways that people are both alike and different. When we recognize, value, and embrace diversity, we are recognizing, valuing, and embracing the uniqueness of each individual.

"Inclusion" means an environment in which all individuals are treated fairly and respectfully; are valued for their distinctive skills, experiences, and perspectives; have equal access to resources and opportunities; and can contribute fully to the organization's success." (ALA, 2017)

The three concepts are intricately linked. ALA's definition places equity at the forefront, followed by diversity and then inclusion, while other works address diversity first, then equity, and inclusion. Jones (1999) notes the usefulness of using a broad and inclusive definition of "diversity" to "introduc[e] to and rall[y] support for the concept" (p. 8) as everyone can identify with personal characteristics which make them unique. However, it is vital that the concept of "equity" is also included in diversity and inclusion discussions given that "considering individual and group equity means understanding and working affirmatively to amend historical and present misrepresentation" (Jones, 1999, p. 8). Improving equity contributes to full and meaningful participation in the workplace. In other words, inclusion cannot exist without first acknowledging differences and addressing inequities.

Despite these commitments to diversity and inclusion, it is well known that the LIS profession in North America is largely homogeneous along racial and ethnic lines with $82 \%$ of librarians reported as White, non-Hispanic from U.S.-based ARL libraries (Schonfeld \& Sweeney, 2017) compared to $85.5 \%$ of library professionals in U.S. -based ARL libraries identified as White people (Chang, 2013). As such, libraries have engaged in various efforts to recruit a more diverse library workforce along racial and ethnic representations, including diversity initiatives, internship, and scholarship programs (Dewey \& Keally, 2008), library residency programs (Pickens \& Coren, 2017) and the use of anti-racist hiring practices (Brook et al., 2015). Much of this literature addresses the recruitment of historically underrepresented racial and ethnic in the U.S. But it is equally important to consider the multiple dimensions of diversity beyond traditional categories of race and ethnicity, including gender identity, sexual identity, physical and mental ability, and indigeneity as part of the recruitment process.

Although many organizations strive to build an inclusive work environment, a truly inclusive organization develops over time, with effort and intentionality. Gardenswartz and Rowe (2010) developed a four-stage paradigm to explain the process of diversity and inclusion in an organization: 1) Equal Employment Opportunity (EEO) and Affirmative Action (AA), 2) valuing differences, 3) managing diversity, and 4) inclusion (pg. 451). At the EEO and AA stage, an organization focuses on legal compliance and changing organizational demographics (also known as a quantitative approach). At stage 2 - valuing differences, organizations approach diversity beyond compliance and focus on creating an environment in which employees feel valued and accepted for their differences. At stage 3 - managing diversity, organizations actively build a diverse workplace and leverage employee differences to achieve organizational goals and stage 4 - inclusion, a truly inclusive organization incorporates all previous stages, but real change in organizational cultures occurs and employees are treated with respect and feel a sense of belonging.

Many organizations, including libraries, aspire to achieve a stage 4 inclusive work environment as part of their diversity management goals. While the Gardenswartz and Rowe (2010) paradigm

The International Journal of Information, Diversity, \& Inclusion, 5(3), 2021

ISSN 2574-3430, jps.library.utoronto.ca/index.php/ijidi/index

DOI: $10.33137 /$ ijidi.v5i3.36202 
stresses that diversity and inclusion goes beyond the EEO and AA categories, the authors also posit that the "intent of embracing diversity is not to replace affirmative action but to build on the critical foundation laid by workplace equity programs. Affirmative action, valuing differences, managing diversity, and inclusion go hand-in-hand, each reinforcing the gains of the other" (p. 450). Diversity management then focuses on the best ways to manage and leverage differences in the workplace, and often involve the implementation of specific actions and strategies to build a diverse and inclusive workplace, including recruiting diverse talent.

The diversity statement is one example of a diversity management tool used by many organizations. These philosophical statements signal an organization's culture, values, and commitment to diversity and inclusion and are often found on job advertisements. According to Mestre (2011) these statements:

sometimes originate from a mission statement. It may be included to supplement a mission statement by articulating a commitment to diversity. It may be a working definition or statement to use as one goes about trying to accomplish the initiatives related to diversity. Its intention may be to keep diversity at the forefront and may include goals. One value is that it lets the public know why the library values ... diversity (p. 105).

Carnes et al. (2019) describe the characteristics of effective institutional diversity statements: aspirational and not implying that diversity goals are already met, "emphasiz[ing] personal autonomy to promot[ing] diversity," defin[ing] diversity broadly and using "multicultural messages rather than colorblind statements" (p. 23). In other words, effective diversity statements reflect Gardenswartz and Rowe's (2010) stage 4 - inclusion characteristics which move beyond compliance and include various dimensions of diversity beyond the traditional racial and ethnic categories.

Diversity statements are vital to an organization's perceived attractiveness in a globalized world and are impactful. Research suggests that organizations with strong diversity statements may deter racially intolerant individuals from applying to jobs as well as influence ethnic minorities application decisions (Brown et al., 2006). Diversity statements, whether on an organization's website or included in the job advertisement, are influential. They tell stories of how an organization perceives itself or how it wants to be perceived, but the diversity statement could potentially provide clues as to which stage of diversity and inclusion an organization currently occupies.

\section{Employment Equity and the Canadian Context}

As discussed previously, EEO and AA compliance is the first stage of building and becoming an inclusive organization. In Canada, there are legal protections from discrimination, namely through the Canadian Charter of Rights and Freedoms. In recognition that certain groups experience exclusion, inequality, discrimination, lack of access, and opportunities to employment, the Canadian government introduced the Employment Equity Act to correct these conditions and disadvantages (Employment Equity Act, SC (1995), c. 44)). Canada's Employment Equity Act applies the term "Aboriginal peoples" to refer to Indigenous peoples, including the Métis (persons of mixed Indigenous and European heritage), and Inuit. This article uses the more inclusive term "Indigenous peoples" to refer to the Canadian government's use of the term Aboriginal in the context of employment equity. The Act also uses the term "visible minorities"

The International Journal of Information, Diversity, \& Inclusion, 5(3), 2021

ISSN 2574-3430, jps.library.utoronto.ca/index.php/ijidi/index

DOI: $10.33137 /$ ijidi.v5i3.36202 
for racialized persons who are non-Indigenous, who are non-Caucasian in race or non-white in color.

Employers wishing to conduct business with the Canadian government are required to implement employment equity plans and policies to identify and eliminate employment barriers faced by the four designated groups: women, Aboriginal peoples (Indigenous, Inuit or Métis), persons with disabilities, and members of visible minorities (Employment Equity Act, SC (1995)). The four official designated employment equity-seeking groups do not include gender identity (outside of the binary male/female categories) or sexual orientation, though those from the LGBTQ+ community arguably face similar forms of employment barriers.

These employment equity requirements apply to Canadian colleges and universities under the Federal Contractors Program (FCP). Contractors are required to:

a) collect workforce information;

b) complete a workforce analysis and an achievement report;

c) establish short-term and long-term numerical goals; and

d) make reasonable efforts to ensure that reasonable progress is made towards having full representation of the four designated groups within its workforce. (Employment and Social Development Canada, 2015)

One critique of the FCP is that it does not indicate or specify what these "reasonable efforts" are or look like to ensure the full representation of these equity-seeking groups. As a result, many organizations have full control over the interpretation of how they will fulfill this requirement. Although the Employment Equity Act and the FCP does not explicitly state a requirement to have job advertisements include equal opportunity/diversity statements in their postings, this appears to be an accepted practice as many Canadian job advertisements include such statements. But most organizations aspire to move beyond a stage 1 compliance model of diversity to a stage 4 inclusive organization. How is this reflected in job advertisements? Do diversity statements provide a clue as to how inclusive an organization truly is? Do these statements move beyond the simple message of "we are an equal opportunity employer"? Dali and Caidi (2017) advocate for the concept of "Diversity by Design" (DbD)-intentional integration of diversity from the beginning rather than an afterthought into all aspects of LIS, including the workforce. Using this concept, if we are to hire a diverse library workforce it is therefore important to examine the diversity messages included in all aspects of the recruitment stage.

This study aims to explore the diversity statements embedded in job advertisements for academic librarian positions at Canadian universities, and the possible messages and themes conveyed about the institution's level of diversity and inclusion commitment and management. Potential future studies are also addressed.

\section{Literature Review}

Various business studies explore the perception of organizational attractiveness based on diversity statements with some mixed results as outlined extensively in Smith et al. (2004). Most of these studies suggest that ethnic minorities are attracted to organizations with diversity

The International Journal of Information, Diversity, \& Inclusion, 5(3), 2021

ISSN 2574-3430, jps.library.utoronto.ca/index.php/ijidi/index

DOI: $10.33137 /$ ijidi.v5i3.36202 
statements (Williams \& Bauer, 1994; Rau \& Hyland, 2003) or affirmative action statements (Smith et al., 2004). Williams and Bauer (1994) conducted an experiment in which students were presented with one of two brochures for a fictional company: one with the standard "Company $X$ is an employment equity/Affirmative Action (AA) employer" phrasing only at the end of the text and the second brochure which included the standard phrasing from the first brochure plus an expanded statement proactively including the company's commitment to respecting individuals and equal access for women, minority groups, people with disabilities and veterans. Regardless of race and gender, students who read the second statement-expanded statement around commitment to diversity-rated the company more attractive. Interestingly, minority groups favored the company more than majority (White) groups regardless of which statement they read, suggesting the importance of any type of diversity statements to minorities.

While much of the research on diversity statements look at ethnic and minority demographics, there are different dimensions of diversity beyond these characteristics. For instance, research on gender diversity statements is also common, but these studies tend to focus on binary notions of gender (male/female) and job attractiveness to women (Windscheid et al., 2016), and not necessarily on transgendered or other gender identities.

Most studies on organizational diversity statements focus on the company's website rather than job advertisements. Of note is Rubaii-Barrett and Wise's (2007) work which examined equal employment opportunity (EEO) statements on the websites of state government Human Resource (HR) agencies in the U.S. They examined the language of EEO statements to see whether they went "beyond the boilerplate phrasing," but they also looked at diversity messages reflected in both text (online mission statements) and visual messages (images of diverse workers). The study found that the majority of American HR state websites only included the required standard phrasing around being an "equal opportunity employer" or "AA" statements.

Point and Singh (2003) studied the diversity statements of various European corporate websites to develop diversity dimension categories beyond the typical demographics, or "visible differences," including geographic differences, opinions/beliefs/orientations, social status, education/person/educational background, and so on (p.757). Expanding on Gardenswartz and Rowe's (1993) original three-stage model, Singh and Point (2004) then studied the diversity statements of 241 European companies to develop a model of different stages of diversity, or "diversity management", in these organizations:

a) Rejecting difference: the diversity is a non-issue/invisible approach

b) Protecting difference: avoiding discrimination approach

c) Assimilating difference: the equal opportunities management approach

d) Respecting difference: the respect and capabilities approach

e) Valuing difference: the valuing individuals and diversity approach

f) Strategic diversity management: the diversity management for competitive advantage approach. (Singh \& Point, 2004, p. 307)

Ideally, an organization would move beyond a model of diversity management where differences are rejected to one where differences are valued, there is strategic use of diversity in all

The International Journal of Information, Diversity, \& Inclusion, 5(3), 2021

ISSN 2574-3430, jps.library.utoronto.ca/index.php/ijidi/index

DOI: $10.33137 /$ ijidi.v5i3.36202 
functions, and the work environment is inclusive. Rubaii-Barrett and Wise (2007) applied Singh and Point's (2004) six-category model to develop their own scheme to analyze the frequency of diversity-related messages found in U.S. government state mission statements on HR websites. The categories they developed were:

a) No mention of diversity

b) Compliance, non-discrimination

c) Diversity with no reason

d) Representative bureaucracy justification

e) Valuing and respecting difference

f) Strategic benefits of diversity

g) No mission statement on website.

Rubaii-Barrett and Wise's study found that "when diversity is mentioned in the mission, it is most commonly stated as a value without any explanation of why it is important, or it is presented in terms of the agency's respect for individual differences" (2007, p. 28). Therefore, ideally, diversity statements will include this as a value to the organization.

Often there is the anecdotal perception that many job advertisements have boilerplate or generic statements about diversity to the effect of "Company $X$ is an equal opportunity employer" or "women/minorities are encouraged to apply,", which reflects a compliance or legalistic model of diversity. These standardized statements appear perfunctory and, often this leads applicants to doubt the veracity of the employer's commitment to diversity. In a New Zealand study, McNab and Johnston (2002) explored gender differences in the rating of an organization's attractiveness based on three types of EEO statement provided in a job advertisement: 1) no EEO statement, 2) minimal EEO statement, and 3) extensive EEO statement. The study found that women rated organizations with extensive EEO statements more favorably, while men rated organizations with minimal EEO statements more favorable. This study, however, did not explore perception by race or ethnicity (all participants were White) or other dimensions of diversity, such as disability, gender identity or sexual identity.

Rubaii-Barrett and Wise (2007) also examined the equal employer opportunity (EEO) statements and developed a classification model for these statements:

a) Standard EEO/affirmative action (AA) compliance statements

b) Standard EEO/AA plus Americans with Disabilities Act (ADA) compliance statements

c) Extensive EEO/AA/ADA plus support for diversity statements

d) No EEO statement on agency website (p. 31)

While neither of these models fit perfectly to the context of this study, elements from Point and Singh's (2003) diversity dimension categories and Rubaii-Barrett and Wise (2007) EEO statement

The International Journal of Information, Diversity, \& Inclusion, 5(3), 2021

ISSN 2574-3430, jps.library.utoronto.ca/index.php/ijidi/index

DOI: $10.33137 /$ ijidi.v5i3.36202 
classification model informed parts of the design and analysis of this current study. Whereas Rubaii-Barrett and Wise's (2007) research focused on U.S. state agencies, Point and Singh's (2003) work focused on European organizations, there were no studies found which examined the Canadian context. Nonetheless, there are significant differences in the history and development of approaches to DEI in Canada compared to the U.S. and Europe.

Despite the amount of relevant research around diversity statements, organizations, and job advertisements produced in the area of organizational studies, the current library literature does not explore diversity statements in library job advertisements. Mestre (2011) analyzed the visibility of diversity efforts on 107 ARL library websites and found that $37 \%$ of ARL libraries had diversity concepts embedded in their strategic plan and $27 \%$ had the concept included in a values statement (p. 104). Mestre's (2011) study only explored the visibility of diversity messages on the websites of ARL libraries but did not examine the statements found in job advertisements. More recently, Clifton (2019) examined the diversity statements of university libraries at schools with an ALA-accredited LIS program to understand the themes coded in these statements. Clifton (2019) identified "reasons for diversity" and "categories of diversity" as the most common themes found in these academic library diversity statements (p. 18-19). Further themes explored include the "Library as" a Provider of Opportunity for Diversity and the library as Acting Upon Diversity (p. 21). Other studies (Okamoto \& Polger, 2012; Ndwandwe \& Onyancha, 2011; Croneis \& Henderson, 2002) analyzed library job advertisements for specific skills or competencies advertised, but none examined diversity statements in the library context. This study will attempt to fill the gap in the library literature by exploring the use of diversity statements and messages in a sample of advertisements for academic librarian positions in Canada.

\section{Purpose and Research Questions (RQs)}

Given the lack of research on the diversity statements contained in job advertisements within the LIS literature, the purpose of this exploratory study is to gain an understanding of academic librarian job advertisements from Canadian universities and their diversity statements. Research objectives are to:

a) gain insights into the prevalence of diversity statements in job advertisements;

b) develop a typology or model of diversity statements contained in job advertisements for future study;

c) understand the level of diversity and inclusion built into these job advertisements; and

d) identify and make recommendations of particular areas and themes for further studies

The following four research questions posed here address these research objectives:

RQ1. How many job advertisements have diversity statements?

RQ2. Are there differences between Association of Research Libraries (ARL) libraries and non-ARL libraries?

RQ3. What types of diversity statements are presented?

The International Journal of Information, Diversity, \& Inclusion, 5(3), 2021

ISSN 2574-3430, jps.library.utoronto.ca/index.php/ijidi/index

DOI: $10.33137 /$ ijidi.v5i3.36202 
RQ4. Do diversity statements go beyond the basic statement around equal employer opportunity phrases?

\begin{abstract}
Method
This exploratory study provides a content analysis of a small sample of Canadian academic librarian and archivist positions advertised on the University of Toronto Faculty of Information Jobsite from January 1 to December 31, 2018. While other websites (such as the Western University Faculty of Information and Media Studies) also post librarian positions, they do not provide an archive of job postings and therefore were not used as a source of sampling.
\end{abstract}

The job advertisements analyzed were limited to full-time (permanent or contract) librarian or archivist positions advertised in Canadian universities and posted on the website for the year beginning January 2018. Part-time positions were excluded as these advertisements were thought to be less detailed than full-time positions. Senior library administrative positions, such as Associate University Librarians or Dean/Associate Deans of Libraries positions, were also excluded from the sample as it was felt that these types of searches warranted different and specialized recruitment treatment than non-administrative positions. Advertisements written in English, as well as bilingual English and French advertisements, were included; there were two bilingual advertisements, although only the English-language portion was analyzed. Although Canada is a bilingual country (French and English), the researcher is not and therefore only English advertisements are reviewed. As a result of the selection criteria, a final total of 50 job advertisements were selected for analysis.

Multiple job advertisements from the same institution were included to allow for possible variations in diversity statements over the course of the year and potential differences in diversity statements across different library branches, library administrations, or campuses from the same institution. This study used Mestre's (2011) general definition of diversity statements as a "philosophical statement," that is, messages conveyed by the organization and signaling its commitment to DEI through various wording, in its recruiting process and/or institutional culture and value.

NVivo, a qualitative analysis software, was used to capture and organize the online job advertisements and to easily and quickly code and aid in the analysis and retrieval of the data. It is important to understand the limitations and challenges of using qualitative analysis software. The researcher acknowledges some of the challenges and disadvantages to using computer software for analysis, namely the tendency to focus on the quantity of data rather than meaning and the overreliance on the software to do the analysis (St. John \& Johnson, 2000; Zamawe, 2015). As this study only used a small sample of 50 advertisements this was not perceived as a relevant issue and the author was able to gather context and meaning from each sample data. The researcher also printed copies and reviewed all 50 advertisements outside of the software. The time investment to learn the software is an equally important factor to consider when choosing software. In anticipation of using a larger sample of data in future studies beyond this exploratory study, the researcher attended a two-day training workshop (Using Computers in Qualitative Analysis: An NVivo 12 For Windows Workshop) to learn the software and workshopped this topic during the training. The ability to test out and work on this research topic while learning the software was helpful in shaping the research study. The researcher's institution also provided a group license discount for the software application and as such, affordability and software support were factors in the choice of application.

The International Journal of Information, Diversity, \& Inclusion, 5(3), 2021

ISSN 2574-3430, jps.library.utoronto.ca/index.php/ijidi/index

DOI: $10.33137 /$ ijidi.v5i3.36202 
Research notes and memos were also created in NVivo to keep track of observations, questions and possible avenues to explore further. The sample of 50 job advertisements was entered as cases in NVivo and then classified. First, each case of a job advertisement was classified according to geography, organizational type in terms of ARL vs non-ARL, presence of diversity statement, and location of diversity statement (see Table 1) to explore RQ1 and RQ2. Manifest content ("elements that are physically present and countable" (Gray \& Densten, 1998, p. 420) was analyzed for RQ1 and to easily identify and count the number of job advertisements with diversity statements. At the time of data collection, there were 13 Canadian academic libraries that were members of the ARL.

Table 1. Organization Case Classification

\begin{tabular}{lll}
\hline Case Classification & Description & Examples \\
\hline Geography & Province of institution & Ontario, Quebec \\
Organization type & ARL or non-ARL status & ARL \\
Diversity statement & $\begin{array}{l}\text { Presence of a diversity } \\
\text { statement }\end{array}$ & Yes, No \\
Location of Diversity & $\begin{array}{l}\text { Where the diversity } \\
\text { statement was found in the } \\
\text { job advertisement }\end{array}$ & $\begin{array}{l}\text { Beginning, middle, end, not } \\
\text { applicable }\end{array}$ \\
\hline
\end{tabular}

While diversity statements on an organization's website and in their strategic documents are often easy to locate and identify because labeling and wording such as "diversity statement", "valuing diversity" or "diversity and inclusion" usually indicate that one is reading a diversity statement, locating the diversity statement within the job advertisement requires more effort and consistency. Before one can code for the presence of diversity statements, an understanding of what a diversity statement "looks" like needs to be developed. The author based the identification of a diversity statement on whether indicator words of the main diversity concepts were present and written in the context of a mission, value, priorities, or program. Table 2 lists indicator words for each major diversity concept used to systematically identify potential elements of a diversity statement.

Table 2. Markers of a Diversity Statement

\begin{tabular}{ll}
\hline Concepts & Indicator Words \\
\hline Diversity & $\begin{array}{l}\text { Diversity, diverse, diversification, inclusion, inclusive, equity, } \\
\text { equitable, }\end{array}$ \\
Employment Equity & $\begin{array}{l}\text { Employment equity, equal opportunity, underrepresented, } \\
\text { marginalized, affirmative action, AA, EE }\end{array}$ \\
Women & Women, gendered \\
\hline
\end{tabular}

The International Journal of Information, Diversity, \& Inclusion, 5(3), 2021

ISSN 2574-3430, jps.library.utoronto.ca/index.php/ijidi/index

DOI: $10.33137 /$ ijidi.v5i3.36202 


\begin{tabular}{ll}
\hline Indigenous people & $\begin{array}{l}\text { Indigenous, Aboriginal, Metis, Inuit, First Nations, [specific } \\
\text { Indigenous peoples] }\end{array}$ \\
People with disabilities & $\begin{array}{l}\text { People with disabilities, persons with disabilities, disability, } \\
\text { disabled }\end{array}$ \\
Visible minorities & Visible minorities, racialized, Black, minority, persons of colour \\
Sexual identity & $\begin{array}{l}\text { Sexual identity, LGBTQ, 2SLGBTQ, }{ }^{1} \text { sexual orientation, sexual } \\
\text { minority, lesbian, gay, bisexual, queer }\end{array}$ \\
Gender identity & $\begin{array}{l}\text { Gender identity, non-binary, gender, non-conforming, } \\
\text { transgender, gender minority }\end{array}$ \\
Diversity & $\begin{array}{l}\text { Diversity, diverse, diversification, inclusion, inclusive, equity, } \\
\text { equitable, }\end{array}$
\end{tabular}

Next, content analysis was used to address RQ2, RQ3, and RQ4. After the diversity statement was identified for each job advertisement, each statement was examined for content and then analyzed to determine the level of detail and complexity. The following guiding questions were asked while looking at the data:

1. Does the diversity statement go beyond the standard boilerplate "we are an equal opportunity employer" statement?

2. Does the diversity statement explicitly list each of the four Employment Equity (EE) designated groups (regardless of wording)? Which groups are listed?

3. Are there other groups, communities, or identities listed outside the four EE designated groups? What are they? What terms or phrases are used?

4. Are there other diversity-related words or phrases listed in the statement?

5. Is there other diversity-related information elsewhere in the job advertisement?

NVivo was used to search the text of all job advertisements for word occurrences related to the concept of diversity and the four EE groups, such as "diverse", "diversity", "equity", "inclusion"; "women", "gender"; "Aboriginal", "Indigenous", "Metis", "Inuit"; and "visible minorities", "racialized", to help identify the diversity statement (see Table 2).

Latent content analysis (deep analysis to interpret meaning behind the text) was used to help answer RQ3 and RQ4. Through an iterative process emerging patterns and themes from the text of diversity statements were coded and a diversity statement typology was developed to help classify the types of diversity statements presented in the sample. Point and Singh's (2003) diversity dimensions (geography, visible differences, opinions/beliefs, social status, education, and "other") were also considered when coding themes beyond the four EE designated groups. A constant comparative method was used to systematically ensure the data was consistently categorized.

The International Journal of Information, Diversity, \& Inclusion, 5(3), 2021

ISSN 2574-3430, jps.library.utoronto.ca/index.php/ijidi/index

DOI: $10.33137 /$ ijidi.v5i3.36202 
Once a typology of diversity statements was drafted, these were tested on a small sample of job advertisements and then further developed. This was repeated a number of times to improve and finalize the four-category diversity statement typology model (see Table 5). During the development of the diversity statement typologies there were two notable cases which did not fall neatly into the four proposed categories. While one sample advertisement did not explicitly list the specific four designated employment equity groups chosen by the author but instead referred to "traditionally underrepresented groups", it was still coded as a T4 type because it included other markers of expanded diversity management, such as a land acknowledgement and the diversification of ideas.

The second interesting case to categorize was the somewhat unique Indigenous Services librarian posting at one institution. While there was a general diversity statement, which included an Indigenous land acknowledgement, the nature of the position (hiring an Indigenous person) did not allow for the listing of the other three designated equity seeking groups (i.e., women, people with disabilities, and visible minorities). However, given the other indicators of an expanded diversity statement, this was also classified as a T4 statement. All 50 job advertisements were then coded in NVivo by diversity statement type and then rechecked for coding consistency.

\section{Results}

\section{RQ1: How many library job advertisements sampled have diversity statements?}

A count of the presence of diversity statements in the sample job advertisements are presented in Table 3. The findings revealed that almost all, $48(96 \%)$, of the initial 50 sampled job advertisements included diversity statements. Only $4 \%(n=2)$ of the job advertisements sampled did not include any indicators of a diversity statement (i.e., lacking any reference to EE, diversity and inclusion, or specific EE groups).

Table 3. Diversity Statement Counts

\begin{tabular}{ll}
\hline Diversity statement & Number $(n=50)$ \\
\hline Yes & $48(96 \%)$ \\
No & $2(4 \%)$ \\
\hline
\end{tabular}

RQ2 Are there differences between Association of Research Libraries (ARL) libraries and nonARL libraries?

RQ2 examined the presence of diversity statements by organizational type (i.e., ARL libraries vs non-ARL libraries). While all $29(100 \%)$ ARL member libraries' job postings included diversity statements in some form (see Table 4), the two job advertisements lacking identifiable diversity statements or messages were not from ARL member libraries. The results indicate that $9.52 \%$ of non-ARL libraries lacked any presence of a diversity statement in their job advertisements from the initial sample of 50 job advertisements selected. In this regard, there were considerable differences between ARL and non-ARL libraries and the presence of diversity statements.

The International Journal of Information, Diversity, \& Inclusion, 5(3), 2021

ISSN 2574-3430, jps.library.utoronto.ca/index.php/ijidi/index

DOI: $10.33137 /$ ijidi.v5i3.36202 
Table 4. Diversity Statement Count by Organizational Type

\begin{tabular}{lll}
\hline Diversity Statement & ARL Library $(\mathrm{n}=29)$ & Non-ARL Library $(\mathrm{n}=21)$ \\
\hline No & $0(0 \%)$ & $2(9.5 \%)$ \\
Yes & $29(100 \%)$ & $19(90.5 \%)$ \\
\hline
\end{tabular}

\section{$R Q 3$ What types of diversity statements are presented?}

Next, RQ3 analyzed the remaining job advertisements with diversity statements $(n=48)$ for patterns. Based on this content analysis, a four-category typology of diversity statements was developed: Typology 1 (T1) Boilerplate; Typology 2 (T2) Employment Equity; Typology 3 (T3) Diversity; an Typology 4 (T4) Expanded Diversity Management. Table 5, below, provides the name of each typology category, its description, and a representative statement from one of the job advertisements sampled. Each unique feature of the diversity statement for that level category or typology is highlighted in bold to illustrate why the sample was coded in that manner. Further details about these typologies are provided in the Discussion section.

Table 5. Diversity Statement Typology

\begin{tabular}{|c|c|c|}
\hline Typology & Description & Sample Statement \\
\hline T1 Boilerplate & $\begin{array}{l}\text { General blanket statement } \\
\text { about diversity or equity only. }\end{array}$ & $\begin{array}{l}\text { "We are an equal opportunity } \\
\text { employer" }\end{array}$ \\
\hline $\begin{array}{l}\text { T2 Employment } \\
\text { Equity (EE) }\end{array}$ & $\begin{array}{l}\text { Statement invites applications } \\
\text { from the four EE groups } \\
\text { (women, Indigenous peoples, } \\
\text { visible minorities and people } \\
\text { with disabilities) only }\end{array}$ & $\begin{array}{l}\text { "The University of } X \text { is an equal } \\
\text { opportunity employer. We strongly } \\
\text { encourage applications from women, } \\
\text { Aboriginal peoples, persons with } \\
\text { disabilities and members of visible } \\
\text { minorities." }\end{array}$ \\
\hline T3 Diversity & $\begin{array}{l}\text { Invites applications from all } \\
\text { named four EE groups plus other } \\
\text { identity groups }\end{array}$ & $\begin{array}{l}\text { "X is actively committed to diversity } \\
\text { and the principles of employment } \\
\text { equity and invites applications from } \\
\text { all qualified candidates. Women, } \\
\text { Aboriginal peoples, members of } \\
\text { visible minorities, people with } \\
\text { disabilities, and lesbian, gay, } \\
\text { bisexual, transgender, and queer } \\
\text { (LGBTQ) persons are encouraged to } \\
\text { apply and to voluntarily self-identify } \\
\text { as a member of a designated group as } \\
\text { part of their application". }\end{array}$ \\
\hline
\end{tabular}

The International Journal of Information, Diversity, \& Inclusion, 5(3), 2021

ISSN 2574-3430, jps.library.utoronto.ca/index.php/ijidi/index

DOI: $10.33137 /$ ijidi.v5i3.36202 


\begin{tabular}{lll}
\hline T4 Expanded & Invites applications from four & "Integral to this path is the \\
Diversity & EE groups, plus other social & placement of equity, diversity and \\
inclusion as fundamental to our & froups, and welcomes other & institutional culture. Our current \\
forms of diversification beyond & academic plan outlines each as core \\
characteristics. & values and we work to embed them in \\
& all that we do. \\
& X University welcomes those who \\
& have demonstrated a commitment to \\
& upholding the values of equity, \\
& diversity, and inclusion and will \\
& assist us to expand our capacity for \\
diversity in the broadest sense. In \\
addition, to correct the conditions of \\
disadvantage in employment in \\
Canada, we encourage applications \\
from members of groups that have \\
been historically disadvantaged and \\
marginalized, including First Nations, \\
Metis and Inuit peoples, Indigenous \\
peoples of North America, racialized \\
persons, persons with disabilities, and \\
those who identify as women and/or \\
2S \\
LGBTQ+" \\
\end{tabular}

RQ4 Do diversity statements go beyond the basic statement around equal employer opportunity phrase?

Table 6. Diversity Statement Count by Typology and Organizational Type

\begin{tabular}{|c|c|c|}
\hline Diversity statement type & $\begin{array}{l}\text { ARL } \\
(n=29)\end{array}$ & $\begin{array}{l}\text { Non-ARL Library } \\
(n=19)\end{array}$ \\
\hline T1 Boilerplate & $2(6.9 \%)$ & $2(10.5 \%)$ \\
\hline T2 Employment Equity & $2(6.9 \%)$ & $2(10.5 \%)$ \\
\hline T3 Diversity & $3(10.3 \%)$ & $6(31.6 \%)$ \\
\hline T4 Extended Diversity & $22(75.9 \%)$ & $9(47.4 \%)$ \\
\hline
\end{tabular}

Table 6 provides a breakdown of diversity statements by type and organizational type. There were four job advertisements classified as T1 boilerplate diversity statements: two from ARL institutions $(6.9 \%)$ and two (10.52\%) from non-ARL member institutions. The same pattern emerges with T2 Employment Equity category diversity statements: two were from ARL

The International Journal of Information, Diversity, \& Inclusion, 5(3), 2021

ISSN 2574-3430, jps.library.utoronto.ca/index.php/ijidi/index

DOI: $10.33137 /$ ijidi.v5i3.36202 
institutions (6.9\%) and two (10.52\%) from non-ARL member institutions. T3 Diversity statements were the second largest category of diversity statement identified: $10.34 \%$ from ARL libraries and $31.5 \%$ from non-ARL libraries. However, the vast majority of ARL libraries (22 out of 29; 75.86\%) displayed T4 Expanded Diversity statements compared to non-ARL libraries (9 out of 19; 47.37\%); this aligns with ARL's stated strategic priority on advancing diversity in libraries. However, as presented in Figure 1, there is a substantial gap (28.49 points) between the percentage of T4 Expanded Diversity statements from ARL and non-ARL libraries. Overall, the results indicated that, contrary to anecdotal evidence, most diversity statements were detailed and complex and moved beyond the boilerplate or vague (T1) statements across both ARL and non-ARL libraries (see Figure 1).

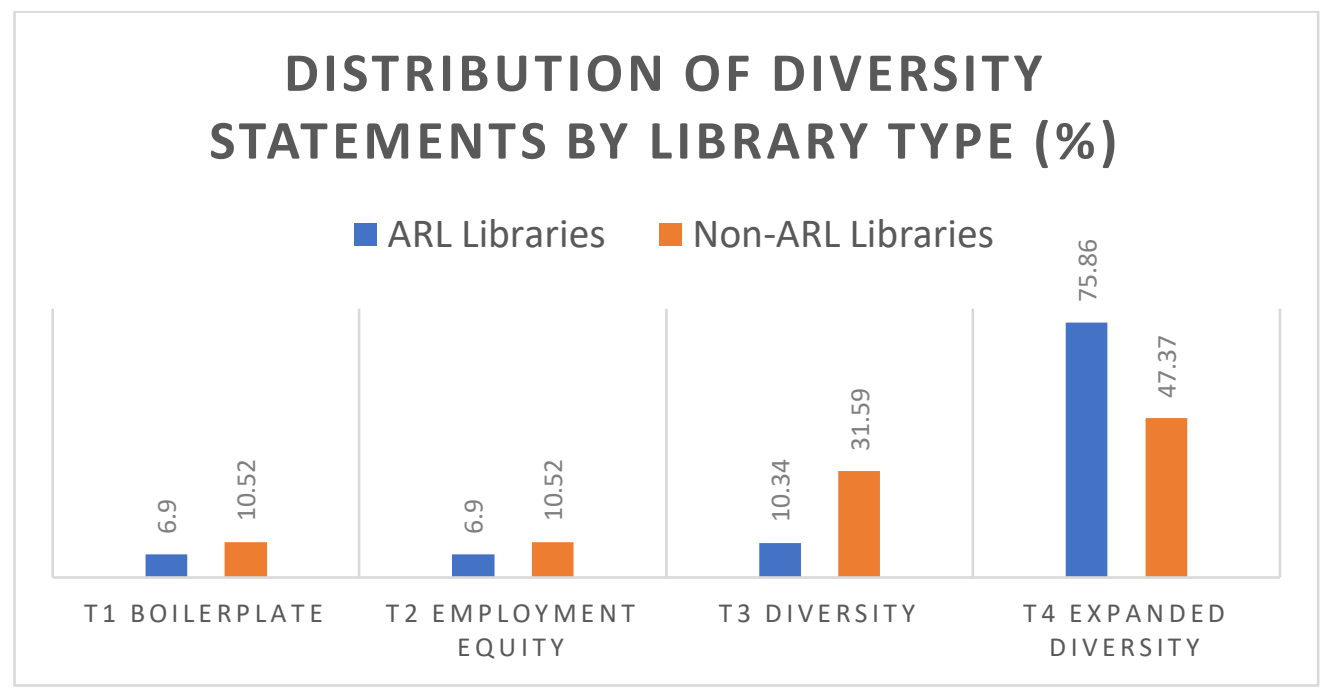

Figure 1. Distribution of Diversity Statements by Library Type (\%)

\section{Discussion}

This exploratory study investigated the presence and nature of diversity statements of job advertisements for Canadian academic librarian and archivist positions. Results suggest that most Canadian academic libraries in the sample studied (96\%) provide some form of a diversity statement in their job advertisements. The sentiment that most job advertisements are apt to use the boilerplate statement "we are an equal opportunity employer" appears to be purely anecdotal from this study because almost $92 \%(n=44)$ of diversity statements studied were from the T2, T3 and T4 categories combined, beyond the standard equal opportunity employer blanket statement. This might suggest the level of thought and commitment in signaling the importance of diversity and inclusion at these Canadian academic libraries.

DEl are stated priorities and values of many LIS associations and organizations. Notably, the ARL has invested much time, effort, and resources toward the initiatives to improve the representation of historically disadvantaged groups. For this reason, the comparison between statements from ARL libraries vs non-ARL libraries was included. Results suggest that Canadian ARL libraries have more diversity/expanded diversity (T3 or T4) statements than their non-ARL counterparts. Is this a sign that ARL libraries are more progressive? More detailed research

The International Journal of Information, Diversity, \& Inclusion, 5(3), 2021

ISSN 2574-3430, jps.library.utoronto.ca/index.php/ijidi/index

DOI: $10.33137 /$ ijidi.v5i3.36202 
exploring the non-ARL libraries may shed further light as to why these types of libraries had so few T4 diversity statements. What is unknown is whether or not this is a result of the propensity for large research libraries to be located in larger, metropolitan areas with more diverse populations and acceptance of diversity or if this is a strong indicator of ARL's influence in building a diverse library force. What about the institutions which did use boilerplate statements? Further analysis could explore results by the type of library, location (urban/metropolitan versus rural/suburban) by province and other organizational types (e.g., public libraries, college libraries) and so forth.

\section{Beyond Race and Ethnicity}

Looking at the analyzed diversity statements, it is heartening to see some evolution in their content beyond the expected blanket boilerplate statements and the signs that we are moving beyond the employment equity model to a more diverse and even inclusive message. Diversity statements under the employment equity model traditionally looked at the four designated groups underrepresented or disadvantaged in the Canadian workplace, namely, women, racialized groups, people with disabilities, and Indigenous peoples. However, there were a number of advertisements examined which included statements welcoming LGBTQ+ identities ("gender identity", "sexual orientation") in addition to the four traditionally legally protected groups in Canada. This marks a shift away from a compliance model of equity (T2) to a diversity type model which includes other groups and identities beyond legal requirements (T3 and T4). A content analysis of LGBTQ+ categories (both usage of the term LGBTQ+ more broadly, but also the specific identities within the LGBTQ+ community) within the job advertisement as well as the corresponding language would make for a fascinating study given the growing trend to include these groups in recruitment efforts. In particular, the Canadian government's traditional category of "woman" as part of the Employment Equity (EE)/Affirmative Action (AA) plan does not address gender diversity (such as transgender, gender non-conforming applicants). How is gender diversity or gender-based equality expressed in diversity statements for these job advertisements? Given that librarianship is a feminized profession with predominantly "women" or cisgender female librarians, often AA plans do not apply to those who self-identify as "women" as there is an over-representation of "women". What are the implications for transgender women applicants for academic librarian positions? Exploring the language of gender-based diversity as an additional category beyond the traditional four EE-seeking groups (see Table 2 - Employment Equity) is one potential area to explore further.

While the diversity statement was the focus of this study, the author often observed the presence of accessibility statements within job advertisements; some within the diversity statement about valuing diversity, while others were listed separately and often immediately after the diversity statement. These accessibility statements varied in length and depth. As many Canadian provinces have accessibility legislation to remove barriers for persons with disabilities, and people with disabilities is an EE category, it would be worthwhile to examine these accessibility statements in greater detail.

Of equal note is the trend of having values-based diversity signified in advertisements with phrases such as "diversification of ideas" or "diversity of ideas" listed in the job advertisements, signaling an organization's willingness to hire candidates who "think outside the box" especially "those who see the world differently, seek change, have a critical eye, and not only notice things that require attention but also dare name these things out loud; those who push the envelope and disrupt the established order; or simply those who stand out" (Dali, 2018, p. 2).

The International Journal of Information, Diversity, \& Inclusion, 5(3), 2021

ISSN 2574-3430, jps.library.utoronto.ca/index.php/ijidi/index

DOI: $10.33137 /$ ijidi.v5i3.36202 
Another promising theme noted in this study was the integration of Indigenous (First Nation, Metis, and Inuit) land acknowledgement statements in the general job advertisement, but in some cases in the diversity statement itself. For example, " $X$ university acknowledges that it sits on the traditional, ancestral, and unceded territory of the $X$ " and " $X$ university is located on the traditional territories of the...". With Canada's Truth and Reconciliation Commission of Canada report (2015) and its calls to action to remedy the past injustices and the legacy of colonialism on Canada's First Nations, acknowledging Indigenous people's kinship to the land have become part of the reconciliation process. Clifton's 2019 study of academic library diversity statements at ALA-accredited LIS schools noted that few diversity statements acknowledged "past discrimination/exclusion, and [that] the Statements that were acknowledging, they varied in levels of specificity" (p. 21). This is another possible area of further research. Future studies exploring the nature of these land acknowledgement statements in job advertisements across geography (i.e., provinces), their wording and messages, relationships to other elements found in diversity statements, as well as studies of the development of these statements over time would be useful to assess reconciliation in action.

\section{Limitations}

This research study was exploratory in nature given the lack of literature about diversity statements in job advertisements in LIS. As an exploratory study, there were several limitations to this work; it had a small corpus of job advertisements at Canadian universities and covered a short time frame period of a year. Although there were established criteria for the selection of advertisements, there is the potential for selection bias as only the author selected the advertisements. Future studies would benefit from multiple coders to avoid selection biases in analysis.

Although colleges are also covered under the Federal Contractor program, they were not included in this study. Given the exploratory nature of this study, further areas of study might include a larger corpus of job advertisements over a longer period of time, the inclusion of colleges, but also looking at the EE reports for each institution in tandem with this study. Real organizational change often comes from the leaders within an organization. Future studies which specifically examine the specialized job advertisements for senior library administrators will add another dimension to the study of diversity statements in LIS.

Another weakness is that the role of academic libraries in developing the job advertisement diversity statements is unknown from the samples studied. Recognizing that the larger university or institution undoubtedly plays a great role in developing the diversity statements for most, if not all, of the institution's job advertisements, including librarian positions, it is unclear how autonomous library search committees are in developing their own job advertisements and diversity statements. Although not a focus of this paper, general statements about the library (e.g., mission or vision) and specific librarian/archivist qualifications and desired traits were also examined to see if they included messages around DEI, but very few included diversity messages. Although libraries may not have full control of the job advertisement diversity statements, preliminary findings suggest that they do exercise some agency in designing the library statement (mission, vision) and qualifications/job traits portion of the postings. As mentioned previously, one particular advertisement for an Indigenous Services librarian position had diversity messages stated in the job advertisement and required the successful candidate to have some experience working with the Indigenous community as part of the required qualification. What would happen if all academic librarian positions supported their institutional diversity statements by including

The International Journal of Information, Diversity, \& Inclusion, 5(3), 2021

ISSN 2574-3430, jps.library.utoronto.ca/index.php/ijidi/index

DOI: $10.33137 /$ ijidi.v5i3.36202 
DEI as part of the required qualifications? The "Diversity by Design" framework would integrate diversity throughout the entire job advertisement, aside from the diversity statement which were found predominantly at the end of the job ad in this study. If libraries were to require candidates to demonstrate their experience working in a diverse and inclusive environment or demonstrate their commitment to DEI in the workplace this would send a strong and positive signal to prospective applicants. A practical approach may be for applicants to include a diversity and inclusion statement as to how they will advance diversity and inclusion in their work as part of the application package; this is an emerging practice in faculty searches (Schmaling et al., 2015).

Organizational change is dependent on who leads. This study excluded senior library administrative positions in its analysis, but given the important role that leaders play to drive change, it would be worthwhile to study the diversity statements and expectations for these positions. Senior library administrators, human resources staff, and search committee members in academic libraries have the opportunity to be leaders in their institution by moving beyond the diversity statement to develop and integrate diversity, equity, and inclusion practices at every stage of hiring and employment if they truly desire an inclusive work environment. Further studies examining the job qualifications itself for diversity messages would be beneficial and could potentially result in the expansion of the four typologies of diversity statements developed from this study, which looked at diversity statements predominantly at the end of job advertisements.

\section{Conclusion}

The objectives of this study were met; namely, to gain insights into the prevalence of diversity statements in job advertisements; develop a typology or model of diversity statements contained in job advertisements for future study; understand the level of diversity and inclusion built into these job advertisements; and identify and make recommendations of particular areas and themes for further studies.

The focus of this study was to explore whether organizations went beyond the traditional EE categories (i.e., stage 1 of a diversity and inclusion organizational model) within the diversity statements. The results confirm the prevalence of diversity statements in job advertisements for Canadian academic librarian and archivist positions. From the sample studied, the researcher proposed a four-stage diversity statement typology: T1 Boilerplate, T2 Employment Equity, T3 Diversity, and T4 Expanded Diversity, with each stage a progression from the previous stage. Other models of diversity statements discussed in the literature review (such as Rubaii-Barrett\& Wise, 2007; Point \& Singh, 2003) applied to organizations' websites and other documents and are not useful for analyzing and classifying diversity statements within job advertisements.

This exploratory research is unique in LIS literature and contributes to the general scholarly literature in the development of a diversity statement typology for Canadian job advertisements which may be applied to future studies both within and external to academic libraries and LIS broadly. Insights from this study are practical and are useful for future studies. Recommendations for future studies are included throughout the discussion and limitations sections.

The concepts of diversity and inclusion are often confused or used interchangeably; yet nuances exist among these two concepts. Activist DeRay Mcesson stated: "diversity is about bodies. Inclusion is about culture" (Delistraty, 2017, para. 21). The T4 category was initially designated as "inclusion", however, upon further reflection of the definition of "inclusion", especially based

The International Journal of Information, Diversity, \& Inclusion, 5(3), 2021

ISSN 2574-3430, jps.library.utoronto.ca/index.php/ijidi/index

DOI: $10.33137 /$ ijidi.v5i3.36202 
on the previously mentioned ALA definition, this final category was renamed "expanded diversity management". Real inclusion can rarely be demonstrated in library advertisements, but instead occurs in the workplace environment once the candidate is hired (after the bodies are in place). Inclusion occurs when diversity is integrated into the organization and the organization "sees itself as part of a global community and works to enhance life for employees, customers, the community, and the world" (Gardenswartz \& Rowe, 2010, p.451).

The diversity typologies developed from this study are merely suggested categories to use to analyze the diversity messages in librarian and archivist job advertisements. A diversity paradigm aims to recruit for equity seeking groups (visible minorities, people with disabilities, women, and Indigenous peoples) and other social identity groups (e.g., LGBTQ+ citizens and immigrants). Inclusive organizations, however, move beyond hiring for bodies to intentionally recruit for values-based diversity; provide land acknowledgements; list employee resources such as daycare and health and wellness facilities, and incorporate other elements which recognize the whole employee (the whole self). But most importantly, these organizations intentionally integrate DEI seamlessly into the organization's culture and decision-making process on a daily basis. The diversity challenge will not be solved by hiring $X$ number of underrepresented librarians (be it women, visible minorities, Indigenous people, or people with disabilities), but this is a first step in the diversity continuum in organizations, including libraries.

\section{Endnote}

1 The acronym 2SLGBTQ+ stands for two-spirit, lesbian, gay, bisexual, transgender, queer or questioning, "plus" other sexual identities.

\section{Acknowledgements}

I would like to thank Stella Park at York University's Institute for Social Research for guidance and support in using NVivo and thinking through the research questions. I would also like to thank Keren Dali for reading an earlier draft of the paper and for her invaluable feedback, encouragement, and suggestions.

Funding sources:

This research did not receive any specific grant from funding agencies in the public, commercial, or not-for-profit sectors.

\section{References}

American Library Association. (2006, July 26). Core values of librarianship. Advocacy, Legislation \& Issues. http://www.ala.org/advocacy/intfreedom/corevalues

The International Journal of Information, Diversity, \& Inclusion, 5(3), 2021

ISSN 2574-3430, jps.library.utoronto.ca/index.php/ijidi/index

DOI: $10.33137 /$ ijidi.v5i3.36202 
American Library Association. (2017, July 5). Equity, diversity, inclusion: An interpretation of the Library Bill of Rights. Advocacy, Legislation \& Issues.

http://www.ala.org/advocacy/intfreedom/librarybill/interpretations/EDI

American Library Association. (2020, September 15). ALA and affiliate equity, diversity, and inclusion statements. https: //www.ala.org/advocacy/ala-and-affiliate\%C2\%A0equitydiversity-and-inclusion-statements

Association of Research Libraries. (n.d.). Diversity, equity \& inclusion. https://www.arl.org/category/our-priorities/diversity-equity-inclusion/

Association of Research Libraries (2020, August 26). ARL action plan 2021-2022. https: / / www.arl.org/wp-content/uploads/2020/11/2020.11.02-arl-action-plan-20212022.pdf

Brook, F., Ellenwood, D., \& Lazzaro, A. E. (2015). In pursuit of antiracist social justice: Denaturalizing whiteness in the academic library. Library Trends, 64(2), 246-284. https://doi.org/10.1353/lib.2015.0048

Brown, D. J., Cober, R. T., Keeping, L. M., \& Levy, P. E. (2006). Racial tolerance and reactions to diversity information in job advertisements. Journal of Applied Social Psychology, 36(8), 2048-2071. https://doi.org/10.1111/j.0021-9029.2006.00093.x

Carnes, M., Fine, E., \& Sheridan, J. (2019). Promises and pitfalls of diversity statements: Proceed with caution. Academic Medicine, 94(1), 20-24. https: //doi.org/10.1097/ACM.0000000000002388

Chang, H. F. (2013, April). Ethnic and racial diversity in academic and research libraries: Past, present, and future. In Proceedings of the 2013 ACRL Conference, Indianapolis, IN. (pp. 182-193). Association of College and Research Libraries.

https://www.ala.org/acrl/sites/ala.org.acrl/files/content/conferences/confsandpreco nfs/2013/papers/Chang_Ethnic.pdf

Clifton, N. M. J. (2019). Themes in diversity statements of academic libraries [Master's thesis, University of North Carolina at Chapel Hill]. Carolina Digital Repository. https://doi.org/10.17615/a15s-rc34

Croneis, K. S., \& Henderson, P. (2002a). Electronic and digital librarian positions: A content analysis of announcements from 1990 through 2000. The Journal of Academic Librarianship, 28(4), 232-237. https://doi.org/10.1016/S0099-1333(02)00287-2

Dali, K. (2018). "Culture Fit" as "Anti-Diversity": Avoiding Human Resources decisions that disadvantage the brightest. The International Journal of Information, Diversity, \& Inclusion (IJIDI), 2(4). https://doi.org/10.33137/ijidi.v2i4.32199

Dali, K., \& Caidi, N. (2017). Diversity by design. The Library Quarterly, 87(2), 88-98. https://doi.org/10.1086/690735

Delistraty, C. (2017, July). Building a world of acceptance: A conversation with DeRay Mckesson. Longreads. https://longreads.com/2017/07/04/building-a-world-of-

The International Journal of Information, Diversity, \& Inclusion, 5(3), 2021

ISSN 2574-3430, jps.library.utoronto.ca/index.php/ijidi/index

DOI: $10.33137 /$ ijidi.v5i3.36202 
acceptance-a-conversation-with-deray-mckesson/

Dewey, B., \& Keally, J. (2008). Recruiting for diversity: Strategies for twenty-first century research librarianship. Library Hi Tech, 26(4), 622-629. https://doi.org/10.1108/07378830810920941

Employment and Social Development Canada. (2015, November 13). Federal Contractors Program [Policies]. https://www.canada.ca/en/employment-socialdevelopment/corporate/portfolio/labour/programs/employment-equity/federalcontractors.html

Employment Equity Act, Revised Statues of Canada (1995, c. 44). https: / /lawslois.justice.gc.ca/eng/acts/e-5.401/page-1.html\#docCont

Gardenswartz, L., \& Rowe, A. (1993). Managing diversity: A complete desk reference and planning guide. Irwin.

Gardenswartz, L., \& Rowe, A. (2010). Managing diversity: A complete desk reference \& planning guide (3rd ed.). Society for Human Resource Management.

Gray, J. H., \& Densten, I. L. (1998). Integrating quantitative and qualitative analysis using latent and manifest variables. Quality \& Quantity, 32, 419-431. https: / / link.springer.com/article/10.1023/A:1004357719066

Jones, D. (1999). The definition of diversity: Two views, a more inclusive definition. Journal of Library Administration, 27(1-2), 5-15. https://doi.org/10.1300/J111v27n01_02

McNab, S. M., \& Johnston, L. (2002). The impact of equal employment opportunity statements in job advertisements on applicants' perceptions of organisations. Australian Journal of Psychology, 54(2), 105-109. https://doi.org/10.1080/00049530210001706573

Mestre, L. S. (2011). Visibility of diversity within Association of Research Libraries websites. The Journal of Academic Librarianship, 37(2), 101-108. https://doi.org/10.1016/j.acalib.2011.02.001

Ndwandwe, S. C., \& Onyancha, O. B. (2011). Job functions and requirements for knowledge managers: Lessons for Library and Information Science (LIS) schools in South Africa. Mousaion, 29(2), 211-226. http://hdl.handle.net/10500/5378

Okamoto, K., \& Polger, M. A. (2012). Off to market we go: A content analysis of marketing and promotion skills in academic librarian job ads. Library Leadership \& Management, 26(2), 1-20. https://academicworks.cuny.edu/jj_pubs/6/

Pickens, C., \& Coren, A. (2017). Diversity residency programs: Strategies for a collaborative approach to development. Collaborative Librarianship, 9(2). https://digitalcommons.du.edu/collaborativelibrarianship/vol9/iss2/7

Point, S., \& Singh, V. (2003). Defining and dimensionalising diversity: Evidence from corporate websites across Europe. European Management Journal, 21 (6), 750-761. https://doi.org/10.1016/j.emj.2003.09.015 
Rau, B. L., \& Hyland, M. M. (2003). Corporate teamwork and diversity statements in college recruitment brochures: Effects on attraction. Journal of Applied Social Psychology, 33(12), 2465-2492. https://doi.org/10.1111/j.1559-1816.2003.tb02776.x

Rubaii-Barrett, N., \& Wise, L. R. (2007). From want ads to web sites: What diversity messages are state government projecting? Review of Public Personnel Administration, 27(1), 21 38. http://dx.doi.org/10.1177/0734371X06289040

Schmaling, K. B., Trevino, A. Y., Lind, J. R., Blume, A. W., \& Baker, D. L. (2015). Diversity statements: How faculty applicants address diversity. Journal of Diversity in Higher Education, 8(4), 213-224. https://doi.org/10.1037/a0038549

Schonfeld, R., \& Sweeney, L. (2017). Inclusion, diversity, and equity: Members of the Association of Research Libraries: Employee demographics and director perspectives. Andrew W. Mellon Foundation and Ithaka S+ R. https: //sr.ithaka.org/wpcontent/uploads/2017/08/20170830-Mellon-SR-Report-Inclusion-Diversity-EquityARL.pdf

Singh, V., \& Point, S. (2004). Strategic responses by European companies to the diversity challenge: An online comparison. Long Range Planning, 37(4), 29-318. https://doi.org/10.1016/j.lrp.2004.05.009

Smith, W. J., Wokutch, R. E., Harrington, K. V., \& Dennis, B. S. (2004). Organizational attractiveness and corporate social orientation: Do our values influence our preference for Affirmative Action and managing diversity? Business \& Society, 43(1), 69-96. https://doi.org/10.1177/0007650304263047

St John, W., \& Johnson, P. (2000). The pros and cons of data analysis software for qualitative research. Journal of nursing scholarship, 32(4), 393-397. https://doi.org/10.1111/j.1547-5069.2000.00393.x

Truth and Reconciliation Commission of Canada (2015). We are all Treaty people: Canadian society and reconciliation. In Canada's Residential Schools: Reconciliation (pp. 193222). McGill-Queen's University Press; JSTOR. https://doi.org/10.2307/j.ctt19qghck

University of Toronto. Faculty of Information (iSchool) Jobsite (n.d.). https://ischool.utoronto.ca/job-site/

Williams, M. L., \& Bauer, T. N. (1994). The effect of a managing diversity policy on organizational attractiveness. Group \& Organization Management, 19(3), 295-308. https://doi.org/10.1177/1059601194193005

Windscheid, L., Bowes-Sperry, L., Kidder, D. L., Cheung, H. K., Morner, M., \& Lievens, F. (2016). Actions speak louder than words: Outsiders' perceptions of diversity mixed messages. Journal of Applied Psychology, 101(9), 1329-1341. http://dx.doi.org/10.1037/apl0000107

Zamawe F.C. (2015). The implication of using NVivo software in qualitative data analysis: Evidence-based reflections. Malawi Medical Journal, 27(1), 13-15. https://doi.org/10.4314/mmj.v27i1.4

The International Journal of Information, Diversity, \& Inclusion, 5(3), 2021

ISSN 2574-3430, jps.library.utoronto.ca/index.php/ijidi/index

DOI: $10.33137 /$ ijidi.v5i3.36202 
Norda Bell (nordam@yorku.ca) is Associate Librarian at York University Libraries. She is subject specialist for social work, human rights and equity studies, and linguistics \& applied linguistics. Her current research focus is on diversity, equity, and inclusion and professional development within libraries, as well as critical librarianship. She also serves as the Book Review Editor for IJIDI. 